\title{
Mechanical Properties of Botanical Recycled Concrete under Different Production Conditions
}

\begin{abstract}
Li Liang*1 and Yuya Sakai ${ }^{2}$
${ }^{1}$ KTH Royal Institute of Technology, School of Architecture and the Built Environment, SE-100 44 Stockholm, Phone (+86) 13250501170;

${ }^{2}$ The University of Tokyo, Institute of Industrial Science, 4-6-1 Ce504 Komaba, 153-8505 Tokyo, Phone +81-80-7267-4138.

Abstract: Botanical recycled concrete, or concrete bonded with wood, is formed by heat pressing the mixture of concrete and wooden waste. Botanical recycled concrete is a relatively new material and the relationship between production condition and its real-world performance is not clear yet. This experimental study investigated the influence of several production condition factors on the density and bending strength of botanical recycled concrete. As a result, temperature and mass ratio of concrete powder to wood flour presented significant effects on the density of this botanical recycled concrete. The increase in production temperature resulted in a remarkable increment in density and bending strength. This is probably due to increased wood flowability and accelerated compaction and bonding formation. The fineness of wood flour had a significant effect on improving bending strength. This is attributed to a larger contact surface between the wood substance and concrete particles.
\end{abstract}

Keywords: Recycling, Circularity, Concrete waste, Wood waste, Botanical concrete, Heat pressing

\section{INTRODUCTION}

Concrete is widely used as the primary building material in many construction projects. Consequently, as old concrete structures aged and deteriorated, large quantities of concrete waste were generated due to demolition [1]. Nowadays, most concrete waste is reused as road base or concrete aggregate. Because the use of concrete waste as land filling materials does not lead to the establishment of a closed loop recycling system, and recycling as concrete aggregate inevitably entails quality degradation [2], a complete recycling method of concrete waste was proposed in which the waste is crushed into powder and compacted for recycling [3]. This method requires no new materials and produces no by-products. However, the compaction process requires high pressure, which needs to be reduced for practical applications.

Wood waste is also produced in construction and demolition sites as well as in wooden product industries and urban expansion [4]. Instead of burning wood waste, which is the primary way to dispose it, a part of the waste is recycled by heat pressing it with thermoplastic polymers to form wood plastic composites (WPC) [5]. Wood is also known as a binderless recyclable material because lignin, a component of wood, can serve as a binder [6].

* Corresponding author: lianli@kth.se 
Table 1. Mix design of concrete specimens.

\begin{tabular}{|c|c|c|c|c|c|c|c|c|}
\hline \multirow{2}{*}{ Label } & OPC & BFS & $\mathrm{W}$ & AE & NS or LS & BFSS & NG or LG & BFSG \\
\cline { 2 - 9 } & \multicolumn{9}{|c|}{ Unit $\left(\mathrm{kg} / \mathrm{m}^{3}\right)$} \\
\hline OPC-C & 432 & 0 & 162 & 1.1 & 760 & 0 & 954 & 0 \\
\hline B50-C & 216 & 216 & 158 & 6.5 & 754 & 0 & 949 & 0 \\
\hline BSBG100-C & 436 & 0 & 152 & 6.5 & 0 & 802 & 0 & 902 \\
\hline LS-C & 478 & 0 & 191 & 0.0 & 727 & 0 & 955 & 0 \\
\hline
\end{tabular}

OPC: Ordinary Portland cement, BFS: Blast furnace Slag, W: Water, AE: Air entraining agent, NS: Normal sand, LS: Limestone sand, NG: Normal gravel, LG: Limestone gravel, BFSS: Blast furnace slag sand, BFSG: Blast furnace slag gravel

Using this property of wood, a novel recycling technology of concrete and wooden waste was proposed [7], where both waste materials are crushed as powder and mixed. Botanical recycled concrete, or concrete bonded with wood, is formed by heat pressing the mixture. Lignin and cellulose from the wood are expected to act as bonding and reinforcement materials, respectively, as these are their natural functions in plants. Botanical recycled concrete is a relatively new material, and even if it has been studied before [8], the relationship between production condition and its real-world performance is not clear yet.

In this experimental study, the effects of four production condition factors on density and bending strength of botanical recycled concrete are examined. These factors are: (1) mass ratio of concrete and wood wastes, (2) property of the original concrete specimens, (3) wood particle size, and (4) pressing temperature. Optimum production conditions are also discussed.

\section{MATERIALS}

The wooden waste species used in this experiment is Japanese cedar. Wooden waste was milled and sieved through mesh sizes of $1,0.5$, and $0.178 \mathrm{~mm}$ to prepare the wooden waste flour. To eliminate the influence of natural water content before heat compaction, the wooden waste flour was dried at $105^{\circ} \mathrm{C}$ until a constant weight was achieved.

The concrete waste was prepared from concrete samples aged one year. The mix design of concrete specimens is shown in Table 1. These specimens were cured in water for 28 days, then stored in a room at $20{ }^{\circ} \mathrm{C}$ and an average relative humidity of $60 \%$ before prepared for this experiment. It is worth noting that humidity in the room was not controlled. Afterwards, the concrete specimens were crushed, milled, and sieved through a $0.3-\mathrm{mm}$ mesh.

\section{METHOD}

The concrete waste powder and wooden waste flour were mixed, filled in a steel mould, and heatpressed into a plate specimen, as shown in Figure 1 (a). A heating plate was used to produce intended temperatures. A hydraulic pressing machine can provide the design compaction pressure and maintain that compaction for the desired time span. Samples of $5 \times 50 \times 65 \mathrm{~mm}$ were produced under a compaction pressure of $50 \mathrm{MPa}$ applied for $5 \mathrm{~min}$. The production condition variables are: concrete to wood mass ratio of $2: 1,1: 1$, and $1: 2$; wood particle size of $0.178-1 \mathrm{~mm}$; and compaction temperature of $180-220^{\circ} \mathrm{C}$. To examine variations in the data, three samples were produced and tested for each production condition. 
The bending strength of samples was tested with a three-point bending test instrument using a universal testing machine, as shown in Figure 2. Support points were $5 \mathrm{~mm}$ away from the sample edge. The loading point was on the centre of the sample. The peak force was obtained to calculate the bending strength.

Bending strength was calculated as follows:

$$
R=(3 F L) /\left(2 W t^{2}\right)
$$

where $R$ is the sample bending strength (MPa), $F$ is the peak force obtained from the universal testing machine $(\mathrm{N}), L$ is the loading distance $(\mathrm{mm}), W$ is the sample width $(\mathrm{mm})$, and $t$ is the sample thickness (mm). In this study, a loading distance $L$ of $55 \mathrm{~mm}$ was used. 


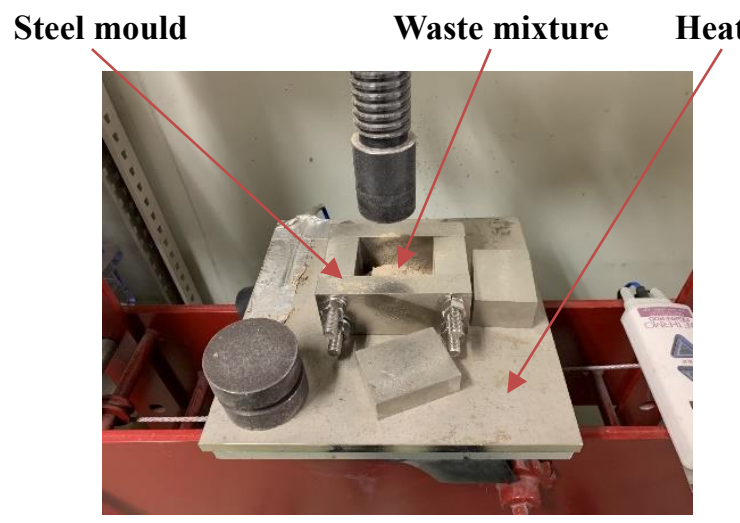

(a) Setup for heat compaction
Heating plate

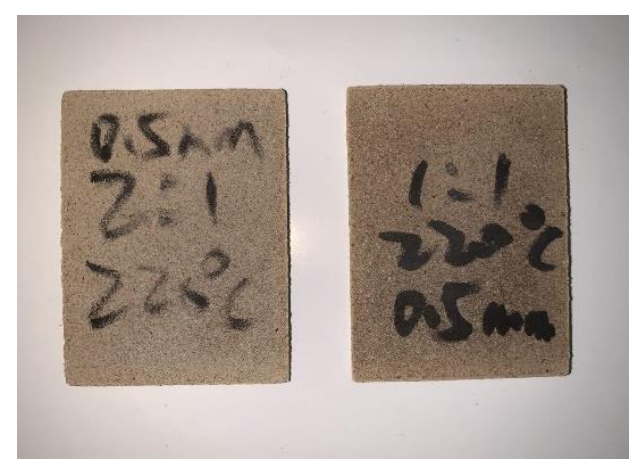

(b) Example of prepared samples

Figure 1. Heating powder compaction and samples

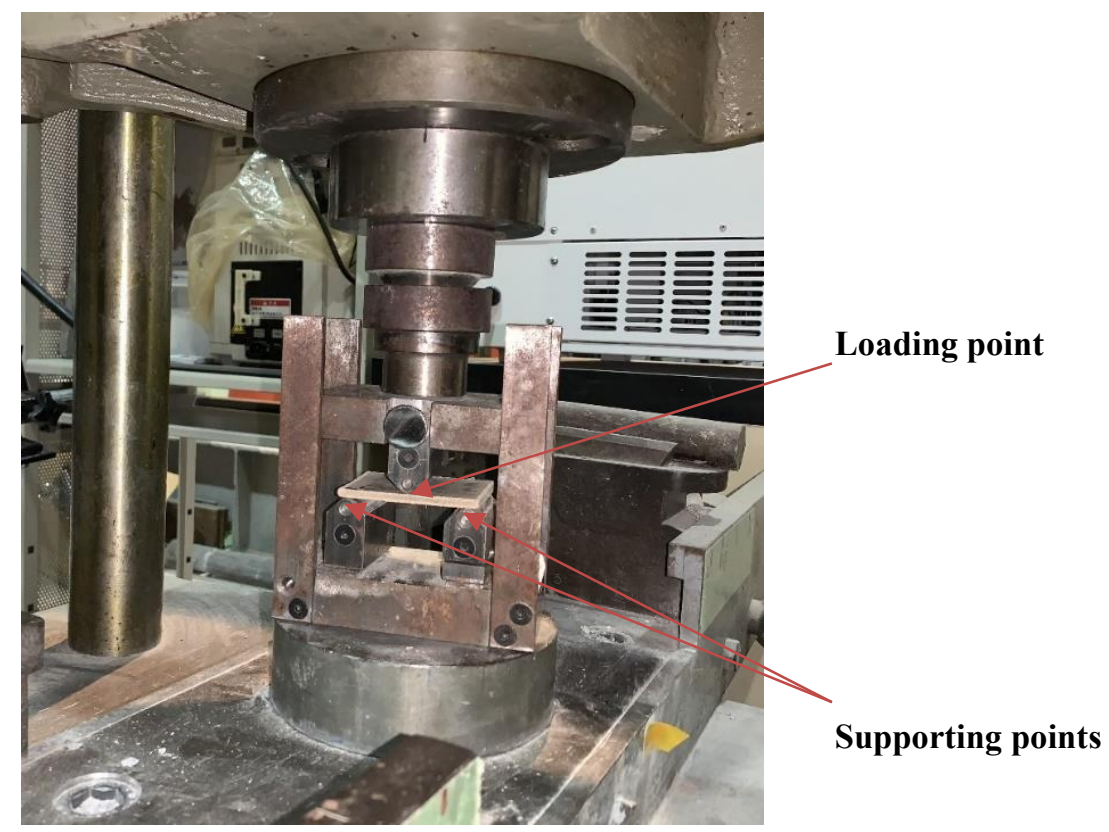

Figure 2. Bending strength test setup

\section{RESULTS AND ANALYSIS}

Figure 3 shows the density and bending strength results for the samples prepared with the various concrete mix designs (see Table 1). The difference in these variables is very small among the specimens, indicating that the effect of different concrete properties is negligible. In the bending strength test, all samples exhibited tensile failure on the bottom, whereas no compression failure was observed on the top. This demonstrates that the bonding or fibres failed before the concrete particles were crushed, which explains why the concrete waste proportion showed negligible effects on bending strength. 


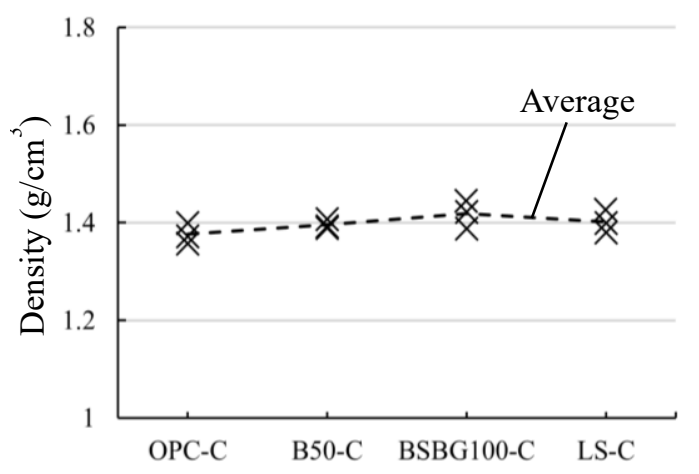

(a) Density

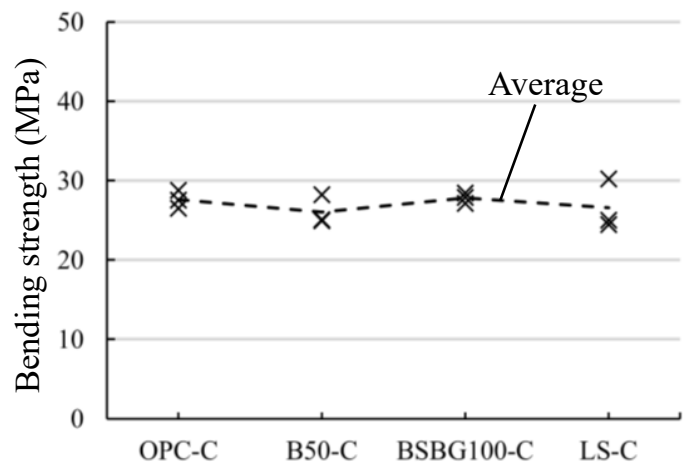

(b) Bending strength

Figure 3. Density (a) and bending strength (b) for the different type of concrete mixes

The density and bending strength variations with heat pressing temperature are shown in Figure 4. These figures show that the botanical recycled concrete density and bending strength greatly increase with increasing production temperature. Under higher temperature, wood is subjected to a higher degree of fusibility, which affects the mobility of lignin and contributes to filling the space between particles with wood substance easier [9]. As a result, the compaction and bonding between particles were improved, reflected in the increase of density and bending strength with temperature.

Figure 5 shows the relation between density and bending strength and the concrete-to-wood mass ratio. The results indicate that bending strength is improved when a higher percentage of wooden waste is present. This result is reasonable because the quantity of bonding and reinforcement materials, lignin and cellulose in wood, increased as the proportion of wood waste increased. Note that when the mass ratio of wood increased from 1:1 to $1: 2$, the bending strength of samples produced under $220{ }^{\circ} \mathrm{C}$ decreased. A probable cause is thermal decomposition of the wood substance [10]. This result indicates that there is an optimum temperature for achieving a desired bending strength.

According to Figures 4-5, in terms wood particle size, the results indicate that the fineness of wooden waste does not accelerate compaction. The density shows small differences, but has a significant effect on increasing and improving bending strength, especially when finer wooden waste particles were used. The improvement in bending strength is probably due to the larger contact surface area between the wood substance and concrete particles when finer wooden waste was used.

In this study, specimens were prepared with a compaction pressure of $50 \mathrm{MPa}$, which is not suited for practical applications. Even though a lower compaction pressure reduces the strength of the specimens, the bending strength of the samples prepared for this study is much higher than that of concrete (approximately $5 \mathrm{MPa}$ ). The highest bending strength was almost $50 \mathrm{MPa}, 10$ times higher than that of normal concrete. Therefore, a lower compaction pressure will be sufficient to produce practical products. 

$+1 \mathrm{~mm}$
$\times 0.5 \mathrm{~mm}$
$\Delta 0.178 \mathrm{~mm}$
- - $1 \mathrm{~mm}$ Average
$-0.5 \mathrm{~mm}$ Average
$----0.178 \mathrm{~mm}$ Average
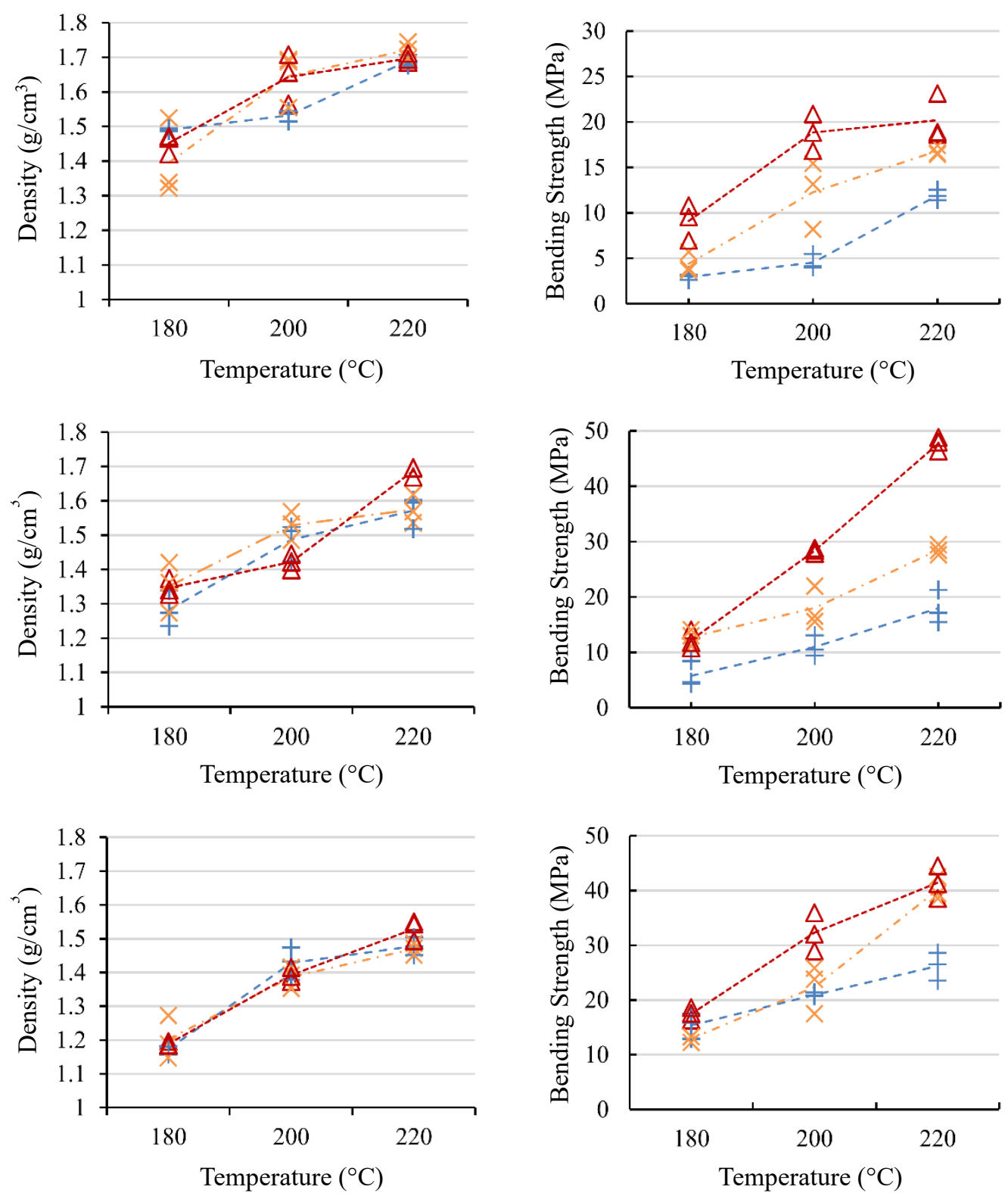

Figure 4. Density (left panels) and bending strength (right panels) of samples with mass ratio of 2:1 (top), 1:1 (center) and 1:2 

$+1 \mathrm{~mm}$
$\times 0.5 \mathrm{~mm}$
$\Delta 0.178 \mathrm{~mm}$
- - $1 \mathrm{~mm}$ Average
$-0.5 \mathrm{~mm}$ Average
----0.178 mm Average

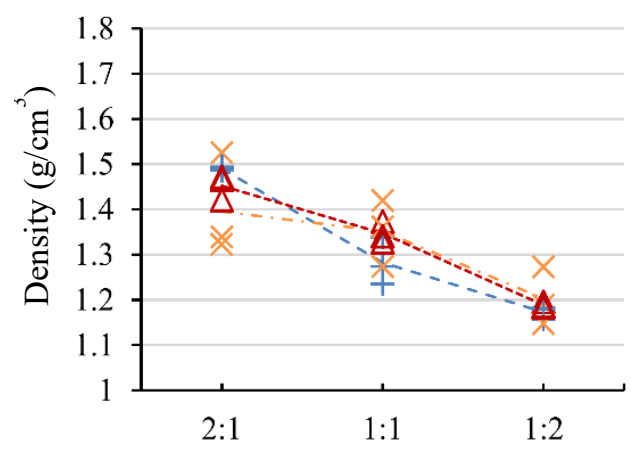

Mass ratio (concrete : wood)

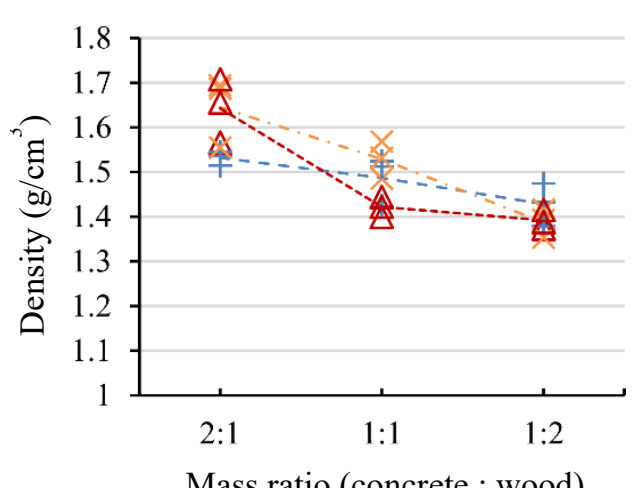

Mass ratio (concrete : wood)

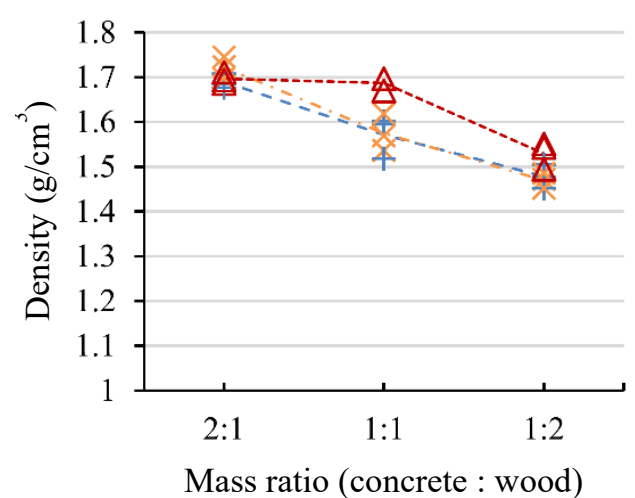

Mass ratio (concrete : wood)

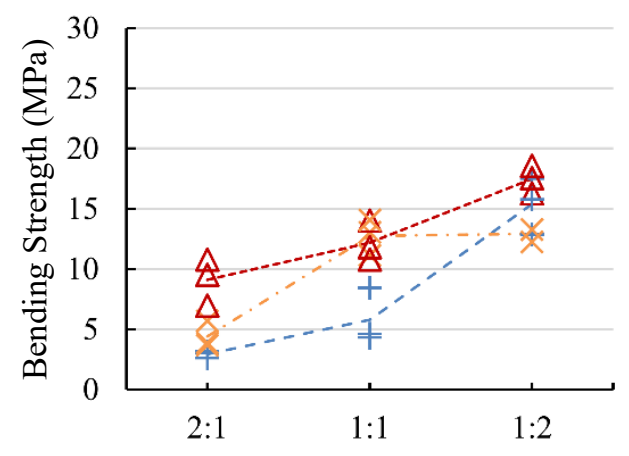

Mass ratio (concrete : wood)
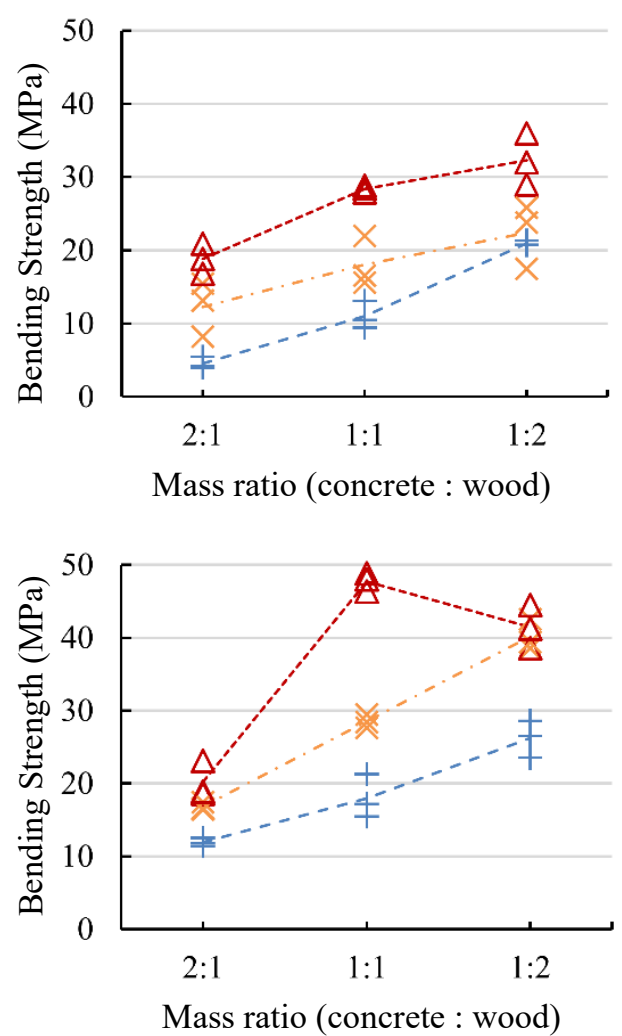

Mass ratio (concrete : wood)

Figure 5. Density (left panels) and bending strength (right panels) of samples under $180^{\circ} \mathrm{C}$ (top), $200^{\circ} \mathrm{C}$ (center) and $220^{\circ} \mathrm{C}$ (bottom) 


\section{CONCLUSIONS}

This experimental study investigated the influence of several production condition factors on the density and bending strength of a novel botanical recycled concrete. Following are the main conclusions drawn from the results obtained and subsequent analysis:

1. Temperature and mass ratio of concrete powder to wood flour presented significant effects on the density of this botanical recycled concrete.

2. The increase in production temperature resulted in a remarkable increment in density and bending strength. This is probably due to increased wood flowability and accelerated compaction and bonding formation.

3. The fineness of wood flour had a significant effect on improving bending strength. This is attributed to a larger contact surface between the wood substance and concrete particles.

\section{REFERENCE}

1. Chooi Mei Mah, Takeshi Fujiwara, Chin Siong Ho. (2017). Concrete Waste Management Decision Analysis Based on Life Cycle Assessment. Chemical Engineering Transactions, 56, 2017, 26-30. DOI: 10.3303/CET1756005.

2. Fuminori Tomosawa, Takafumi Noguchi, Masaki Tamura. (2004). The Way Concrete Recycling Should Be. Journal of Advanced Concrete Technology, 3(1), 3-16. DOI: 10.3151/jact.3.3.

3. Yuya Sakai, Biruktawit Taye Tarekegne, Toshiharu Kishi. (2016). Recycling of hardened cementitious material by pressure and control of volumetric change. Journal of Advanced Concrete Technology, 14(2), 47-54. DOI: 10.3151/jact14.47.

4. Scott Lyon, Brian Bond. (2014). What's "Urban Wood Waste"?. Forest Products Journal. 64(5-6), 166-170. DOI: 10.13073/FPJ-D-14-00023.

5. Mladen Sercer, Pero Raos, Maja Rujnic Sokele. (2009). Processing of wood-thermoplastic composites. International Journal of Material Forming, 2, 721-724. DOI: 10.1007/s12289009-0654-y.

6. Daihui Zhang, Anjiang Zhang, Lixin Luke Xue. (2015). A review of preparation of binderless fiberboards and its self-bonding mechanism, Wood Science and Technology, 49(4), 661-679, DOI:10.1007/s00226-015-0728-6

7. Yuya Sakai, Kai Minagawa, Futoshi Katsuki. (2020). Development of new construction material using concrete and wooden wastes. Seisan kenkyu, 72(2), 213-217. DOI: 10.11188/seisankenkyu. 72.213.

8. Li Liang, Yuya Sakai. (2020). Experimental Study of the Bending Strength of Recycled Concrete and Wooden Waste by Heating Compaction. Preprints 2020, 2020020312. DOI: 10.20944/preprints202002.0312.v1.

9. Omid Hosseinaei, David P. Harper, Joseph J. Bozell, Timothy G. Rials. (2017). Improving Processing and Performance of Pure Lignin Carbon Fibers through Hardwood and Herbaceous Lignin Blends. International Journal of Molecular Sciences, 18(7), 1410. DOI: 10.3390/ijms18071410.

10. Haiping Yang, Rong Yan, Hanping Chen, Dong Ho Lee, Chuguang Zheng. (2007). Characteristics of hemicellulose, cellulose and lignin pyrolysis. Fuel, 86(12-13), 1781-1788. DOI: 10.1016/j.fuel.2006.12.013. 
This is the author's version of an extended abstract submitted to International Conference on Circularity in the Built Environment (CiBEn 2020)

Extended abstract:

Li Liang and Yuya Sakai: Mechanical Properties of Botanical Recycled Concrete under Different Production Conditions

L. Liang

KTH Royal Institute of Technology

lianli@kth.se

Y. Sakai

Institute of Industrial Science, The University of Tokyo

ysakai@iis.u-tokyo.ac.jp

http://r.goope.jp/ysakai 